\title{
BMJ open Fate of manuscripts rejected by a non-English-language general medical journal: a retrospective cohort study
}

\author{
Siri Vinther, ${ }^{2}$ Jacob Rosenberg ${ }^{1,2}$
}

To cite: Vinther $S$, Rosenberg J. Fate of manuscripts rejected by a non-English-language general medical journal: a retrospective cohort study. BMJ Open 2011;1:e000147. doi:10.1136/

bmjopen-2011-000147

- Prepublication history for this paper is available online. To view these files please visit the journal online (http://bmjopen.bmj.com).

Received 26 April 2011 Accepted 1 June 2011

This final article is available for use under the terms of the Creative Commons Attribution Non-Commercial 2.0 Licence; see http://bmjopen.bmj.com

${ }^{1}$ Department of Surgical Gastroenterology, Herlev Hospital, University of Copenhagen, Herlev, Denmark

${ }^{2}$ Ugeskrift for Læger (Journal of the Danish Medical Association), Copenhagen, Denmark

Correspondence to Siri Vinther;

sirivinther@hotmail.com

\begin{abstract}
Objective: The objective of this study was to determine whether, where and when manuscripts were published following rejection by the Journal of the Danish Medical Association, a general medical journal published in Danish. Similar previous studies have focused on specialty/subspecialty journals published in English.
\end{abstract}

Design: Manuscripts rejected during a 4-year period were searched for in PubMed and Embase in order to assess the percentage of manuscripts subsequently published in other journals. In addition, characteristics of both the published manuscripts and the journals in which they were evaluated.

Results: Of 198 rejected manuscripts, 21 (10.6\%) were eventually published after a median of 685 days (range 209-1463). The majority of these were original research, published in English-language specialty/ subspecialty journals. The median number of citations per article was 2-3 (IQR 0.5-9.5, depending on the database searched).

Conclusions: $10.6 \%$ of the rejected manuscripts were eventually published in other journals, mainly English-language specialty journals. This proportion was considerably lower than that for other journals that have studied the fate of rejected manuscripts. Manuscript translation could be a barrier for resubmitting to English-language journals with larger readerships, thus hindering the dissemination of knowledge to the international community.

\section{OBJECTIVE}

Since 1839, the Journal of the Danish Medical Association (Ugeskrift for Læger-UfL) has been published on a weekly basis. It is one of the oldest general medical journals in the world, and the only Danish, peer-reviewed medical journal indexed in Medline.

The journal publishes editorials, original articles, systematic reviews, non-systematic reviews and case reports with an average of 10 articles per week.

The objective of this study was to determine whether, where and when manuscripts were published following rejection by UfL.

\section{ARTICLE SUMMARY}

Article focus

- To determine whether, where and when manuscripts were published following rejection by a general medical journal published in a language other than English

\section{Key messages}

- $10.6 \%$ of the rejected manuscripts were eventually published in other journals, a proportion considerably lower than that for other journals that have studied the fate of rejected manuscripts

- Manuscript translation could be a barrier for resubmitting to English-language journals with larger readerships. Scientific journals publishing in small languages should consider publishing original research in a major language such as English in order to facilitate the dissemination of scientific results

Strengths and limitations of this study

- PubMed and Embase were used to search for rejected manuscript eventually published in other (indexed) journals; previous studies have searched only PubMed for rejected manuscripts. However, even when searching both databases, the number of search results (published manuscripts) would most likely be an underestimate, as some manuscripts could be published in nonindexed journals.

- This study deals with a general medical journal published in a small language; previous studies have focused on specialty/subspecialty journals published in English.

The journal is published in Danish and thus serves a relatively small readership. Yet, the fate of manuscripts rejected by UfL is not only of national interest. This study could reveal that science communicated in a (small) national language may not cross borders. This could be of particular concern when no national alternative for manuscript resubmission exists. Then, language alone precludes the dissemination of knowledge that could otherwise benefit national as well as international scientific communities. 


\section{METHODS}

The editorial office of UfL kindly gave access to all manuscripts rejected by the journal. All unsolicited manuscripts rejected during the years 2002-2005 were included in the study, a total of 198. For each rejected manuscript, an enclosure provided information about date of submission, date of refusal, manuscript type, author(s) and commentaries by peer reviewers. In addition, copies of editorial rejection letters were obtainable.

PubMed and Embase were used to search for rejected manuscript eventually published in other (indexed) journals. By default, only the first author's surname and initials were searched for. If the author had a very common name, a combination of the first author's surname and the last author's surname was tried. If only one author was listed, a combination of the author's surname and a subject keyword was tried.

When searching PubMed and Embase for manuscripts, the time interval was not restricted. In this way, potential attempts at duplication could be detected (authors having submitted their manuscript to another journal (and getting published) in addition to submitting to UfL). A non-restricted time interval would also provide sufficient opportunity for a manuscript to be published elsewhere.

When a search yielded a potential result in PubMed, Embase or both, the abstract was read. If any doubt existed as to whether the publication corresponded to the manuscript once rejected by UfL, the article was downloaded and read thoroughly. If doubt persisted, the corresponding author was contacted and asked whether this specific manuscript rejected by UfL had been published elsewhere.

For each year (2002-2005), the number of submitted manuscripts, rejected manuscripts and manuscripts subsequently published in (indexed) journals was counted. The proportion between rejected manuscripts and total number of submissions and also the proportion between manuscripts published elsewhere and rejected manuscripts were then calculated. Finally, the distribution of the manuscript types submitted to UfL and the distribution of the manuscript types published elsewhere were analysed.

For every published manuscript, the following was recorded: manuscript type (original research, systematic review, non-systematic review, case report), reason for rejection by UfL and finally number of citations in Scopus, Google Scholar and Web of Science. ${ }^{1-4}$

For every publishing journal, the name, subject, publication language and impact factor were recorded. Seventeen journals were rated for impact by the Institute for Scientific Information. ${ }^{5}$

\section{RESULTS}

Table 1 shows the number of submitted manuscripts to UfL, the number of rejected manuscripts, the proportion between rejected manuscripts and submissions, the number of manuscripts published elsewhere and the proportion between manuscripts published elsewhere and manuscripts rejected by UfL. A total of 198 manuscripts were rejected during the years 2002-2005; the average acceptance rate was $91.8 \%$. Of the manuscripts rejected by UfL, 21 were subsequently published elsewhere.

Based on the editorial rejections letters, two-thirds of the manuscripts eventually published were rejected by UfL because of methodological/scientific reasons. For the rest, the reasons were lack of originality and/or clinical interest.

Table 2 lists the characteristics of the 19 journals that eventually published the 21 manuscripts. All of the articles were published in English. With regard to subject, the majority of the journals would be categorised as specialty/subspecialty journals.

The median time from submission to UfL to publication elsewhere was 685 days (range 209-1463). Six manuscripts were published within 1 year of the original submission to UfL, six manuscripts were published within 2 years, and nine manuscripts were published more than 2 years after the submission to UfL.

Figure 1A shows the relative distribution of submitted manuscripts (2440 in total). Figure 1B shows the relative distribution of the rejected manuscripts eventually published elsewhere (21 in total).

Table 3 lists data for the manuscripts of original research. Overall, $26.8 \%$ of the manuscripts submitted to UfL were manuscripts of original research. Of all the manuscripts rejected by UfL, manuscripts of original research constituted $36.9 \%$. Of all published manuscripts initially rejected by UfL, manuscripts of original research constituted $38.1 \%$. The proportion between published manuscripts of original research and manuscripts of original research rejected by UfL was $11.0 \%$.

Table 1 Manuscripts-submitted, rejected and published elsewhere

\begin{tabular}{llllll}
\hline Year & $\begin{array}{l}\text { Submitted } \\
\text { manuscripts }\end{array}$ & $\begin{array}{l}\text { Rejected } \\
\text { manuscripts }\end{array}$ & $\begin{array}{l}\text { Rejected manuscripts } \\
\text { (percentage of } \\
\text { submissions) }\end{array}$ & $\begin{array}{l}\text { Manuscripts } \\
\text { subsequently } \\
\text { published elsewhere }\end{array}$ & $\begin{array}{l}\text { Published elsewhere } \\
\text { (percentage of rejected } \\
\text { manuscripts) }\end{array}$ \\
\hline 2002 & 555 & 58 & 10.5 & 7 & 12.1 \\
2003 & 707 & 51 & 7.2 & 8 & 15.7 \\
2004 & 585 & 52 & 8.9 & 4 & 7.7 \\
2005 & 593 & 37 & 6.2 & 2 & 5.4 \\
Total & 2440 & 198 & 8.1 & 21 & 10.6 \\
\hline
\end{tabular}


Table 2 Characteristics of the publishing journals

\begin{tabular}{|c|c|c|c|c|}
\hline Journal & $\begin{array}{l}\text { Year of } \\
\text { publication }\end{array}$ & Impact factor* & Subject of journal $^{6}$ & $\begin{array}{l}\text { Language of } \\
\text { journal }\end{array}$ \\
\hline Acta Radiologica & 2006 & 0.884 & Radiology and nuclear medicine & English \\
\hline Acupunture in Medicine & 2002 & & Alternative medicine & English \\
\hline American Journal of Cancer (ceased) & 2004 & & Oncology & English \\
\hline American Journal of Case Reports & 2008 & & Medical sciences & English \\
\hline Archives of Gynecology and Obstetrics & 2006 & $0.666(2007)$ & Obstetrics and gynecology & English \\
\hline $\begin{array}{l}\text { Basic and Clinical Pharmacology } \\
\text { and Toxicology† }\end{array}$ & $2003+2004$ & 1.489 (2005) & $\begin{array}{l}\text { Pharmacy, pharmacology; } \\
\text { enviromental studies, toxicology } \\
\text { and environmental safety }\end{array}$ & English \\
\hline Clinical Rheumatology & 2008 & 1.559 & Rheumatology & English \\
\hline Current Medical Research and Opinion & 2006 & 3.062 & Medical sciences & English \\
\hline Homeopathy & 2006 & $1.041(2008)$ & $\begin{array}{l}\text { Chiropractic, homeopathy, } \\
\text { osteopathy }\end{array}$ & English \\
\hline International Journal for Quality in Healthcare & 2004 & $1.138(2005)$ & Medical sciences & English \\
\hline $\begin{array}{l}\text { International Journal of Hygiene and } \\
\text { Environmental Health }\end{array}$ & 2007 & 1.621 & Public health and safety & English \\
\hline International Urology and Nephrology & 2007 & 0.482 & Urology and nephrology & English \\
\hline Journal of Clinical Densitometry & 2005 & 1.871 & Medical sciences & English \\
\hline Medical Hypotheses & 2005 & 0.92 & Medical sciences & English \\
\hline International Journal of Clinical Pharmacy & 2006 & 0.941 & Pharmacy and pharmacology & English \\
\hline Scandinavian journal of infectious diseases & 2003 & $1.308(2005)$ & Communicable diseases & English \\
\hline Scandinavian Journal of Primary Healthcare & 2006 & 1.541 & $\begin{array}{l}\text { Nurses and nursing; health } \\
\text { facilities and administration }\end{array}$ & English \\
\hline $\begin{array}{l}\text { Surgical Laparoscopy Endoscopy and } \\
\text { Percutaneous Techniques }\end{array}$ & 2005 & 0.865 & $\begin{array}{l}\text { Surgery; gastroenterology; } \\
\text { obstetrics and gynecology }\end{array}$ & English \\
\hline Vaccine & 2004 & 2.822 (2005) & $\begin{array}{l}\text { Allergology and immunology; } \\
\text { veterinary science }\end{array}$ & English \\
\hline
\end{tabular}

As a measure of importance, the number of citations that each article received since its publication was also studied. As the number of citations can differ significantly depending on the database searched, it was considered relevant to search Scopus, Google Scholar and Web of Science. ${ }^{1-3}$

For Web of Science, the median number of citations was two; the IQR was $0.5-6$. The total number of citations was 104 . For Scopus, the median number of citations was two; the IQR was $0.5-5.5$. The total number of citations was 109. For Google Scholar, the median number of citation was three; the IQR was $1.5-9.5$. The total number of citations was 153 . Only two manuscripts have received more than 10 citations in all three databases.

\section{DISCUSSION}

This study found that 21 out of 198 manuscripts rejected by a non-English-language general medical journal were subsequently published in other journals. The majority of these manuscripts were published in specialty/ subspecialty journals. Previous studies, dealing with specialty or subspecialty journals published in English, have reported publication rates of more than $40 \%{ }^{7}$

The majority of manuscripts submitted to UfL between 2002 and 2005 were non-systematic reviews. Most of these manuscripts were probably never resubmitted, at
A Submitted manuscripts - relative distribution

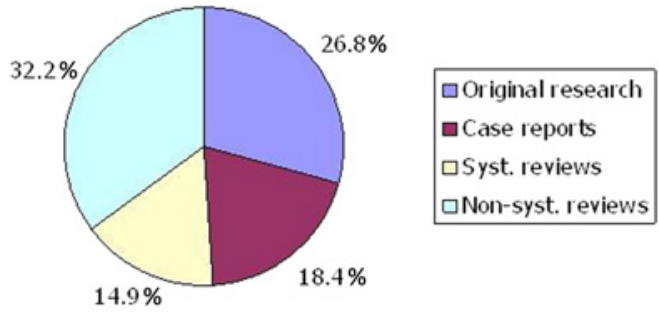

B

Rejected manuscripts published elsewhere - relative distribution

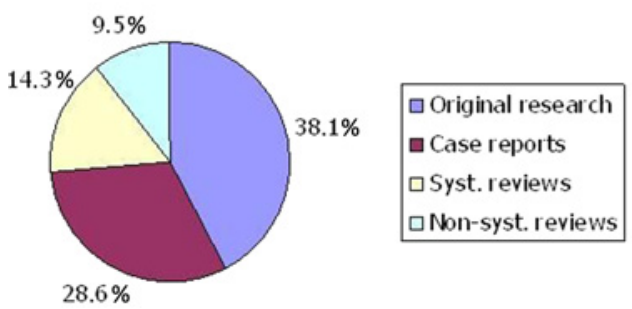

Figure 1 (A) Submitted manuscripts-relative distribution. (B) Rejected manuscripts published elsewhere-relative distribution. 


\begin{tabular}{lllll} 
Table 3 & Manuscripts of original research & & \\
\hline & $\begin{array}{l}\text { Submitted original } \\
\text { manuscripts out of } \\
\text { total no of submitted } \\
\text { manuscripts (\%) }\end{array}$ & $\begin{array}{l}\text { Rejected original } \\
\text { manuscripts out } \\
\text { of total no of rejected } \\
\text { manuscripts (\%) }\end{array}$ & $\begin{array}{l}\text { Published original } \\
\text { manuscripts out of } \\
\text { total no of published } \\
\text { manuscripts (\%) }\end{array}$ & $\begin{array}{l}\text { Published original } \\
\text { manuscripts out of } \\
\text { no of rejected original } \\
\text { manuscripts (\%) }\end{array}$ \\
\hline 2002 & 30.1 & 32.8 & 14.3 & 5.3 \\
2003 & 27.0 & 45.1 & 37.5 & 13.0 \\
2004 & 24.8 & 40.4 & 75.0 & 14.3 \\
2005 & 25.5 & 27.0 & 50.0 & 10.0 \\
Total & 26.8 & 36.9 & 38.1 & 11.0 \\
\hline
\end{tabular}

least not to international journals. Methodological inadequacies, lack of originality or focus on local issues could be reasons for rejecting such manuscripts - if they were to be resubmitted.

Manuscripts of original research were most often published (cf, figure $1 \mathrm{~B}$ and table 3 ). Authors of original research manuscripts might be more persistent and intent on getting published; the process of translating and resubmitting might not be a barrier for authors who already put considerable effort into the research process. For editors, there is an ethical responsibility to publish manuscripts of original research, not least when the findings are of interest to an international audience.

Previous studies have dealt with specialty or subspecialty journals for which reason it has been more obvious to compare impact factors (between journals within the same field). Overall, it seems that publication is attempted first in a journal with a relatively high impact factor. If the manuscript is rejected, it is then submitted to a journal with a higher acceptance rate and lower (or no) impact factor-for example, to national journals publishing in non-English such as UfL. If the manuscript is rejected again, there are not many places left to go. In theory, this could explain some of the discrepancies between the findings of this study and those of previous studies (all dealing with high-impact journals with low acceptance rates).

Previous studies have searched only PubMed for rejected manuscripts. This involves a risk of missing manuscripts published in journals not indexed in this database. When searching for medical literature, Embase is generally regarded an important supplement to PubMed, especially when it comes to European literature. $^{8-11}$ Searching both PubMed and Embase was important in the present study, as two additional manuscripts were retrieved by searching Embase. However, even when searching both databases, the number of search results (published manuscripts) would most likely be an underestimate, as some manuscripts could be published in non-indexed journals-a major limitation to this study.

Another limitation of the study was the potential risk of not identifying all indexed articles. When searching PubMed and Embase, the first author's surname and initials were initially tried. If an author had a very common name-or a long list of publications-a combination with either the last author's name or a subject keyword was tried. This approach should limit the number of overlooked manuscripts; yet, spelling differencies and/or changes in the number or order of authors could lead to an underestimation of the number of manuscripts published in indexed journals.

This study differs significantly from previous studies because it deals with a general medical journal published in a small language (Danish is spoken by only $0.08 \%$ of the world population). ${ }^{12} 13$ Previous studies have focused on specialty/subspecialty journals published in English. It seems a reasonable assumption that language, including translation of manuscripts, could be a potential barrier for resubmission to other journals.

In a broader perspective, this implies that scientific results initially communicated in a small language have international reach only in rare instances. Scientific journals publishing in small languages should acknowledge this problem and consider possible solutions. Since 2009, UfL has published all original articles in English in the open-access journal Danish Medical Bulletin. ${ }^{14}{ }^{15}$ Whether a mono- or bilingual approach is chosen, the aim should be to facilitate the communication of science.

Funding None.

Competing interests None.

Contributors SV and JR made substantial contributions to the conception and design, SV was responsible for the acquisition of data and initial analysis, SV and JR participated in the interpretation of data; SV drafted the article, and SV and JR revised it critically for important intellectual content; SV and JR gave final approval of the version to be published. SV had full access to all of the data in the study and takes responsibility for the integrity of the data and the accuracy of the data analysis.

Provenance and peer review Not commissioned; externally peer reviewed.

Data sharing statement Full dataset available from the corresponding author at sirivinther@hotmail.com.

\section{REFERENCES}

1. Elsevier. SciVerse Scopus. http://www.info.sciverse.com/scopus (accessed 5 May 2011).

2. Google. Google Scholar. http://scholar.google.dk/ (accessed 14 Mar 2011).

3. ISI Web of Knowledge. Web of Science. 2011. http://apps. isiknowledge.com.ep.fjernadgang.kb.dk/WOS_GeneralSearch_input. do?product $=$ WOS\&search_mode $=$ GeneralSearch\&SID $=$ 
R2plPf75MpOlaOmolC @ \&preferencesSaved= (accessed 14 Mar 2011)

4. Kulkarni AV, Aziz B, Shams I, et al. Comparisons of citations in web of science, scopus, and google scholar for articles published in general medical journals. JAMA 2009;302:1092-6.

5. ISI Web of Knowledge. Journal citation reports. http://admin-apps. isiknowledge.com.ep.fjernadgang.kb.dk/JCR/JCR?PointOfEntry= Home\&SID $=$ N115PelPck2NBnb88i3 (accessed 14 Mar 2011).

6. www.ulrichsweb.com. Global Series Directory. http://www.ulrichsweb. com.ep.fjernadgang.kb.dk/ulrichsweb/Search/fullCitation.asp? navPage $=1 \&$ tab $=1 \&$ serial_uid $=18616 \&$ issn $=00415782$ (accessed 14 Mar 2011)

7. Wijnhoven $\mathrm{BP}$, Dejong $\mathrm{CH}$. Fate of manuscripts declined by the British Journal of Surgery. Br J Surg 2010;97:450-4

8. Fangerau $\mathrm{H}$. Finding European bioethical literature: an evaluation of the leading abstracting and indexing services. $J$ Med Ethics 2004;30:299-303.
9. Wilkins T, Gillies RA, Davies K. EMBASE versus MEDLINE for family medicine searches: can MEDLINE searches find the forest or a tree? Can Fam Physician 2005;51:848-9.

10. Kelly L, St Pierre-Hansen N. So many databases, such little clarity: Searching the literature for the topic aboriginal. Can Fam Physician 2008;54:1572-3.

11. Woods D, Trewheellar K. Medline and Embase complement each other in literature searches. BMJ 1998;316:1166.

12. Wikipedia. Languages by Number of Native Speakers. http://en. wikipedia.org/wiki/List_of_languages_by_number_of_native_ speakers (accessed 5 May 2011)

13. Wikipedia. World Population. http://en.wikipedia.org/wiki/ World_population (accessed 5 May 2011).

14. Rosenberg J. [Danish versus English in Ugeskrift for Laeger] (in Danish). Ugeskr Laeger 2009;171:1911.

15. Danish Medical Bulletin. Danish Medical Bulletin. 2011. http://www. danmedbul.dk. 